\title{
OPTIMIZATION OF CLAVULANIC ACID PRODUCTION BY STREPTOMYCES DAUFPE 3060 BY RESPONSE SURFACE METHODOLOGY
}

\section{Daniela A. Viana Marques"; Márcia N. Carneiro Cunha ${ }^{2}$; Janete M. Araújo ${ }^{3}$; José L. Lima-Filho²; Attilio Converti ${ }^{4}$; Adalberto Pessoa-Jr ${ }^{1 *}$; Ana L. Figueiredo Porto ${ }^{5}$}

\begin{abstract}
${ }^{1}$ Departamento de Tecnologia Bioquímico-Farmacêutica, Universidade de São Paulo, São Paulo, SP, Brasil; ${ }^{2}$ Laboratório de Biotecnologia, LIKA, Universidade Federal de Pernambuco, Recife, PE, Brasil; ${ }^{3}$ Departamento de Antibióticos, Universidade Federal de Pernambuco, Recife, PE, Brasil; ${ }^{4}$ CAPES Fellowship/Brazil, Department of Chemical and Process Engineering,
\end{abstract} University of Genoa, Via Opera Pia 15, 16145 Genoa, GE, Italy; ${ }^{5}$ Departamento de Morfologia e Fisiologia Animal, Universidade Federal Rural de Pernambuco, Dois Irmãos, PE, Brasil.

Submitted: August 18, 2010; Approved: January 13, 2011.

\begin{abstract}
Clavulanic acid is a $\beta$-lactam antibiotic which has a potent $\beta$-lactamase inhibiting activity. In order to optimize its production by the new isolate Streptomyces DAUFPE 3060, the influence of two independent variables, temperature and soybean flour concentration, on clavulanic acid and biomass concentrations was investigated in $250 \mathrm{~mL}$-Erlenmeyers according to a $2^{2}$ central composite design. To this purpose, temperature and soybean flour (SF) concentration were varied in the ranges $26-34^{\circ} \mathrm{C}$ and $10-50 \mathrm{~g} / \mathrm{L}$, respectively, and the results evaluated utilizing the Response Surface Methodology. The experimental maximum production of clavulanic acid $(629 \mathrm{mg} / \mathrm{L})$ was obtained at $32^{\circ} \mathrm{C}$ and $40 \mathrm{~g} / \mathrm{L} \mathrm{SF}$ after $48 \mathrm{~h}$, while the maximum biomass concentration $(3.9 \mathrm{~g} / \mathrm{L})$ at $30^{\circ} \mathrm{C}$ and $50 \mathrm{~g} / \mathrm{L}$ soybean flour, respectively. These values are satisfactorily close to those $(640 \mathrm{mg} / \mathrm{L}$ and $3.75 \mathrm{~g} / \mathrm{L}$, respectively) predicted by the model, thereby demonstrating the validity of the mathematical approach adopted in this study.
\end{abstract}

Key words: Clavulanic acid, response surface methodology, production, optimization, streptomyces sp.

\section{INTRODUCTION}

Clavulanic acid (CA) is a $\beta$-lactamase inhibitor that is administered in combination with penicillin group antibiotics to overcome certain types of antibiotic resistance. Despite sharing the $\beta$-lactam ring typical of penicillins, CA has low intrinsic antimicrobial activity. However, such a similarity in chemical structure allows it acting as a competitive inhibitor of $\beta$-lactamases secreted by certain bacteria to confer resistance to $\beta$-lactam antibiotics (30). The combined action as $\beta$-lactamase inhibitor and antibacterial agent makes CA very important both clinically and economically (21).

\footnotetext{
*Corresponding Author. Mailing address: Department of Biochemical and Pharmaceutical Technology, University of São Paulo, Av. Prof. Lineu Prestes, 580, Bloco 16, Cidade Universitária, 05508-000 São Paulo, SP, Brazil.; Tel: +55 113091 3862; Fax: +55 11 3815 6386.; E-mail: pessoajr@usp.br
} 
The pharmacokinetic characteristics of CA supported the development of combined therapy regimens with amoxicillin and ticarcillin, and the therapeutic success of these combination drugs is well recognized. CA formulations have been used widely and effectively in the treatment of a broad range of clinical infections for nearly 20 years (11).

Nowadays, the $\beta$-lactam antibiotics, particularly penicillins and cephalosporins, represent the world's major biotechnology products, with around $65 \%$ of the total world market of antibiotics (10).

Streptomyces is the largest antibiotic-producing genus in the discovered microbial world. Species belonging to this genus still remain an important source of antibiotics. In recent years, screening of natural products, particularly microbial products, has fallen out. Nevertheless, it is becoming increasingly apparent that $99 \%$ of the diverse bacterial species is still unexplored $(10,28,37)$. Thus, the discovery of new Streptomyces species is a challenge for the improvement of CA production.

However, closer inspection of metabolite production patterns among other producers of CA, clavams and cephamycin $\mathrm{C}$ suggests that a strong selective pressure, rather than mere chance, has created actinomycetes that coproduce CA and a $\beta$-lactam antibiotic such as cephamycin C. Among these, several strains of Streptomyces clavuligerus, Streptomyces jumonjinensis, Streptomyces katsurahamanus, and an unclassified Streptomyces sp. are reported to produce CA (15).

The productivity of microbial metabolites is, in general, closely related to the fermentation process $(6,12,18)$. In order to reduce the costs of a bioprocess, it is necessary to develop strains with increased productivity, use inexpensive raw materials, improve filtration properties, perform the process under favorable conditions (30), thus requiring its optimization. Most of previous studies on CA were devoted to the improvement of its production by $S$. clavuligerus (36), for which a final CA concentration of even $1384 \mathrm{mg} / \mathrm{L}$ has recently been reported (31).

However, there are only a few works that deal with high CA producing mutants of this species or other Streptomyces species $(17,19)$ as well as process optimization by statistical design (35).

Statistical design of experiments is a widely used tool for process optimization and control. By a factorial design, the significant factors and their effects can be studied using only a few experiments, thus saving time and reducing the operating costs (4). Response surface methodology (RSM), originally described by Box and Wilson (3), enables evaluation of the effects of many factors and their interactions on response variables. The main advantage of RSM is the reduced number of experimental runs needed to provide sufficient information for statistically acceptable results (9). Therefore, it is less laborious and time-consuming compared to full-factorial experimentation (32).

Aiming at reducing the cost of the process, a new good producer (Streptomyces DAUFPE 3060) is proposed in this study for the production of $\mathrm{CA}$, using a minimal medium composed only of soybean flour and glycerol. In previous study, the influence of the most important process variables on CA production by this strain was screened using a $2^{5-2}$ fractional factorial design, and temperature and soybean flour concentration resulted to be the most significant ones (34). Although the new isolate was not yet characterized, its high performance in CA production with respect to common $S$. clavuligerus strains constituted the main novelty of that study. On the basis of this ground, a $2^{2}$ central composite design combined with RSM was used in this work to select the best values of these two variables able to optimize CA production by the same strain.

\section{MATERIALS AND METHODS}

\section{Reagents}

Potassium clavulanate from Streptomyces clavuligerus was 
used to obtain the calibration curve needed to determine CA concentration. The imidazole used in the CA determination was provided by Sigma Aldrich (São Paulo, São Paulo, Brazil). The salts, glycerol, bacto-peptone, malt extract, and yeast extract used to prepare the media were analytical grade reagents.

\section{Microorganism}

The Streptomyces spp. DAUFPE 3060 strain was kindly provided by the Microorganism Collection of the Department of Antibiotics of the Federal University of Pernambuco, Recife-PE, Brazil. The microorganism, which is still at the stage of characterization, was stored in cryotubes (glycerol 10 $\%, \mathrm{v} / \mathrm{v}$ ) at $-70{ }^{\circ} \mathrm{C}$ and used throughout the present work.

\section{Culture media}

The seed medium had the following composition (in g/L distilled water): glycerol, 15; bacto-peptone, 10; malt extract, 10; yeast extract, $1.0 ; \mathrm{K}_{2} \mathrm{HPO}_{4}, 2.5 ; \mathrm{MgSO}_{4} \cdot 7 \mathrm{H}_{2} \mathrm{O}, 0.75$; $\mathrm{MnCl}_{2} \cdot 4 \mathrm{H}_{2} \mathrm{O}, 0.001 ; \mathrm{FeSO}_{4} \cdot 7 \mathrm{H}_{2} \mathrm{O}, 0.001$; and $\mathrm{ZnSO}_{4} \cdot 7 \mathrm{H}_{2} \mathrm{O}$, 0.001. The $\mathrm{pH}$ of the medium was adjusted to 6.8 with $\mathrm{NaOH}$ $5.0 \mathrm{M}$ before autoclaving at $121{ }^{\circ} \mathrm{C}$ for $15 \mathrm{~min}$. The inoculum medium used in the cultivations, based on that proposed by Maranesi et al. (22), had the following composition (in $\mathrm{g} / \mathrm{L}$ distilled water): glycerol, 10; soybean flour (SF), 20; $\mathrm{K}_{2} \mathrm{HPO}_{4}$, $1.2 ; \mathrm{MnCl}_{2} \cdot 4 \mathrm{H}_{2} \mathrm{O}, 0.001 ; \mathrm{FeSO}_{4} \cdot 7 \mathrm{H}_{2} \mathrm{O}, 0.001 ; \mathrm{ZnSO}_{4} \cdot 7 \mathrm{H}_{2} \mathrm{O}$, $0.001, \mathrm{pH}$ 6.8. The composition of the production medium was similar to that used for the inoculum, except for the concentration of glycerol $(5.0 \mathrm{~g} / \mathrm{L})$ and the SF concentration that was varied according to the selected experimental design.

\section{Fermentation conditions}

Spores of Streptomyces spp. DAUFPE 3060 were obtained from colonies grown on solid culture medium in Petri plates. These colonies were withdrawn and grown in liquid culture medium for $96 \mathrm{~h}$. After determination of initial biomass concentration by dry weight, the spores were lyophilized and stored in glycerol $10 \% \mathrm{v} / \mathrm{v}$. The seed culture was prepared by adding the lyophilized spores $(6.6 \mathrm{~g} / \mathrm{L}$ dry weight $)$ contained in a cryotube with glycerol to $25 \mathrm{~mL}$ of seed medium in $250 \mathrm{~mL}$ Erlenmeyer flasks that were incubated in an orbital shaker at 28 ${ }^{\circ} \mathrm{C}$ and $200 \mathrm{rpm}$ for $24 \mathrm{~h}$. Afterward, $250 \mathrm{~mL}$-Erlenmeyer flasks containing $45 \mathrm{~mL}$ of inoculum medium were inoculated with $5.0 \mathrm{~mL}$ of the seed culture and incubated in an orbital shaker under the same conditions. Then, $5.0 \mathrm{~mL}$ aliquots of this suspension with cells at the exponential growth phase $(24 \mathrm{~h})$ were transferred to $250 \mathrm{~mL}$-Erlenmeyer flasks containing 45 $\mathrm{mL}$ of the production medium. The exponential phase was obtained after $24 \mathrm{~h}$. The 14 production runs, which lasted 168 $\mathrm{h}$, were performed in an orbital shaker at $150 \mathrm{rpm}$ at different temperatures, according to the experimental design described later.

\section{Analytical methods}

The fermentation broth was centrifuged at $5500 \times \mathrm{x} g$ for 20 min at $4{ }^{\circ} \mathrm{C}$, and the cell pellet was washed twice with distilled water and dried to constant weight at $80{ }^{\circ} \mathrm{C}$. The $\mathrm{CA}$ concentration in the fermented broth was determined spectrophotometrically by its reaction with imidazole (2). For this purpose, the increase in the optical density at $311 \mathrm{~nm}$ consequent to the formation of the product [1-(8-hydroxy-6oxo-4-azooct-2-enol)-imidazole] was determined using a spectrophotometer Ultrospec 3000 pro UV/Visible (GE Healthcare, Life Sciences, Uppsala, Sweden). Glycerol concentration was determined according to Hae Bok and Demain (13). All the analyses were performed in triplicate.

\section{Experimental design and data analysis}

In order to quantify the influence of the selected independent variables, specifically soybean flour concentration $\left(v_{1}\right)$ and temperature $\left(v_{2}\right)$, on the responses (concentrations of $\mathrm{CA}$ and biomass), a $2^{2}$ central composite design with threecoded levels leading to 14 experiments was used, which contained a factorial or fractional factorial matrix with center 
points and star points to allow estimation of the curvature (7).

The range and levels of the variables investigated in this study are given in Table 1 . Six tests at the central point were performed to estimate the pure error needed for the analysis of variance, to examine the presence of curvature in the response surface, and to investigate the suitability of the proposed models.

The concentrations of CA and biomass were determined after $48 \mathrm{~h}$, because previous experiments demonstrated that after this time CA degradation begun. The quadratic model to predict the optimal point was expressed by the equation:

$$
\hat{y}=b_{0}+\sum b_{i} x_{i}+\sum b_{i i} x_{i}^{2}+\sum b_{i j} x_{i} x_{j}
$$

where $\hat{y}$ represents the predicted value of the response variables, $b_{0}$ is the intercept coefficient, $b_{i}$ are the linear coefficients, $b_{i i}$ are the quadratic coefficients and $b_{i j}$ are the interaction ones.

Table 1. Levels of factors used in the $2^{2}$ central composite design.

\begin{tabular}{|c|c|c|c|c|c|}
\hline Levels & Low & Central & High & Axial & Axial \\
\hline Coded values & -1 & $\mathbf{0}$ & +1 & $(-\alpha)$ & $(+\alpha)$ \\
\hline$v_{l}-\mathrm{SF}$ concentration $(\mathrm{g} / \mathrm{L})$ & 20 & 30 & 40 & 10 & 50 \\
\hline$v_{2^{-}}$Temperature $\left({ }^{\circ} \mathrm{C}\right)$ & 28 & 30 & 32 & 26 & 34 \\
\hline
\end{tabular}

The statistical significance of the regression coefficients was determined by the Student's $t$-test, and the second-order model equation was determined by the Fischer's test. The effects of unexplained variability in the observed response due to extraneous factors were minimized by randomizing the order of experiments (20).

\section{RESULTS AND DISCUSSION}

\section{Experimental design and optimization by RSM}

The results of a first attempt to point out the main variables influencing the CA production by Streptomyces spp. DAUFPE 3060 were already discussed in previous work (34). For this purpose, the effects of temperature, agitation intensity, $\mathrm{pH}$, glycerol and soybean flour (SF) concentrations were investigated using a $2^{5-2}$ fractional factorial design. The regression analysis showed that both SF concentration and temperature were significant for CA production at probability levels of 95 and $97 \%$, respectively, thereby proving the mostly influencing independent variables. However, the simultaneous variations of five variables in that effort did not enable us to predict their optimum levels, but only suggested ranges of temperature and SF concentration within which subsequent optimization should be focused. This is the objective of the present optimization work.

The main results obtained by Streptomyces DAUFPE 3060 fermentations according to the $2^{2}$ central composite design selected for this study are listed in Table 2. Experiments were planned so as to obtain quadratic models able to describe the $\mathrm{CA}$ and biomass concentrations as simultaneous functions of temperature and SF levels.

The maximum CA production $(629 \mathrm{mg} / \mathrm{L})$ was achieved at $32{ }^{\circ} \mathrm{C}$ and $\mathrm{SF}=40 \mathrm{~g} / \mathrm{L}$ (run 4). Similarly, the maximum biomass concentration $(3.9 \mathrm{~g} / \mathrm{L})$ was observed at $\mathrm{SF}=50 \mathrm{~g} / \mathrm{L}$ and $30^{\circ} \mathrm{C}$ (run 6). 
Table 2. Level combinations of the two independent variables (temperature and SF concentration) used in the $2^{2}$ central composite design, and results of the selected responses (clavulanic acid and biomass concentrations).

\begin{tabular}{lcccc}
\hline \multicolumn{2}{c}{ Independent variables } & \multicolumn{2}{c}{ *Responses } \\
\hline Run & $\begin{array}{c}\text { Temperature } \\
\left({ }^{\circ} \mathbf{C}\right)\end{array}$ & $\begin{array}{c}\text { SF } \\
(\mathbf{g} / \mathbf{L})\end{array}$ & $\begin{array}{c}\text { Clavulanic acid } \\
(\mathbf{m g} / \mathbf{L})\end{array}$ & $\begin{array}{c}\text { Biomass } \\
(\mathbf{g} / \mathbf{L})\end{array}$ \\
\hline $14(\mathbf{C})$ & 30 & 30 & 567 & 3.4 \\
7 & 26 & 30 & 501 & 2.4 \\
$12(\mathbf{C})$ & 30 & 30 & 566 & 3.3 \\
$10(\mathbf{C})$ & 30 & 30 & 567 & 3.1 \\
5 & 30 & 10 & 221 & 1.8 \\
6 & 30 & 50 & 582 & 3.9 \\
2 & 32 & 20 & 377 & 2.0 \\
$13(\mathbf{C})$ & 30 & 30 & 567 & 3.5 \\
$11(\mathrm{C})$ & 30 & 30 & 568 & 3.4 \\
4 & 32 & 40 & 629 & 3.3 \\
$9(\mathrm{C})$ & 30 & 30 & 565 & 3.1 \\
8 & 34 & 30 & 595 & 2.9 \\
3 & 28 & 40 & 562 & 3.0 \\
1 & 28 & 20 & 306 & 1.3 \\
\hline *All values were statistically significant at $95 \%$ confidence level. & & & \\
\hline
\end{tabular}

The experimental data of Table 2 were then used to make regression analyses fitting both responses. The following equations, where the variables take their coded values, express the best models for $\mathrm{CA}$ and biomass concentrations, respectively:

$\hat{y}_{1}=566.67+127.32 x_{1}-84.15 x_{1}^{2}+33.87 x_{2}-10.89 x_{2}^{2}-$ $1.00 x_{1} x_{2}$

$\hat{y}_{2}=3.30+0.75 x_{1}-0.31 x_{1}^{2}+0.21 x_{2}-0.41 x_{2}^{2}-0.10 x_{1} x_{2}$

[4]

where $\hat{y}_{1}, \hat{y}_{2}$ and $x_{1}$ are CA, biomass and SF concentrations, while $x_{2}$ is temperature.

The simultaneous effects of temperature and SF concentration and their interactions on the CA and biomass productions are better visualized in three-dimensional (3-D) graph projections (Figures 1 and 2) using the Response Surface Methodology (RSM).

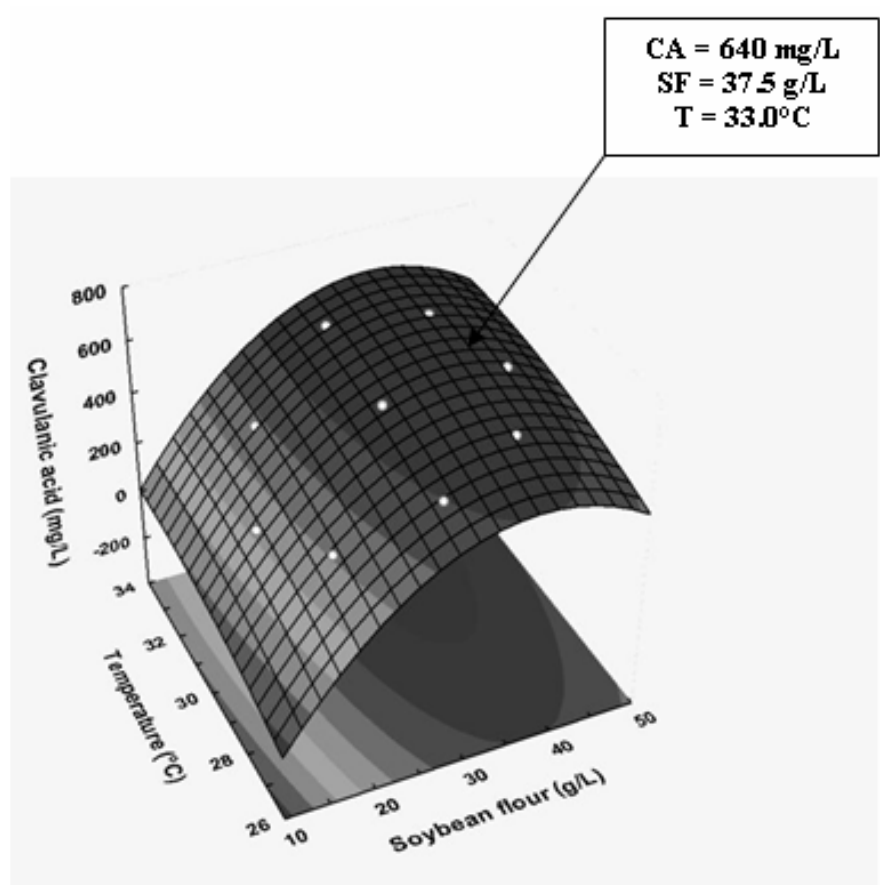

Figure 1. Three-dimensional response surface contour plot showing the simultaneous effects of soybean flour concentration and temperature on CA concentration. 


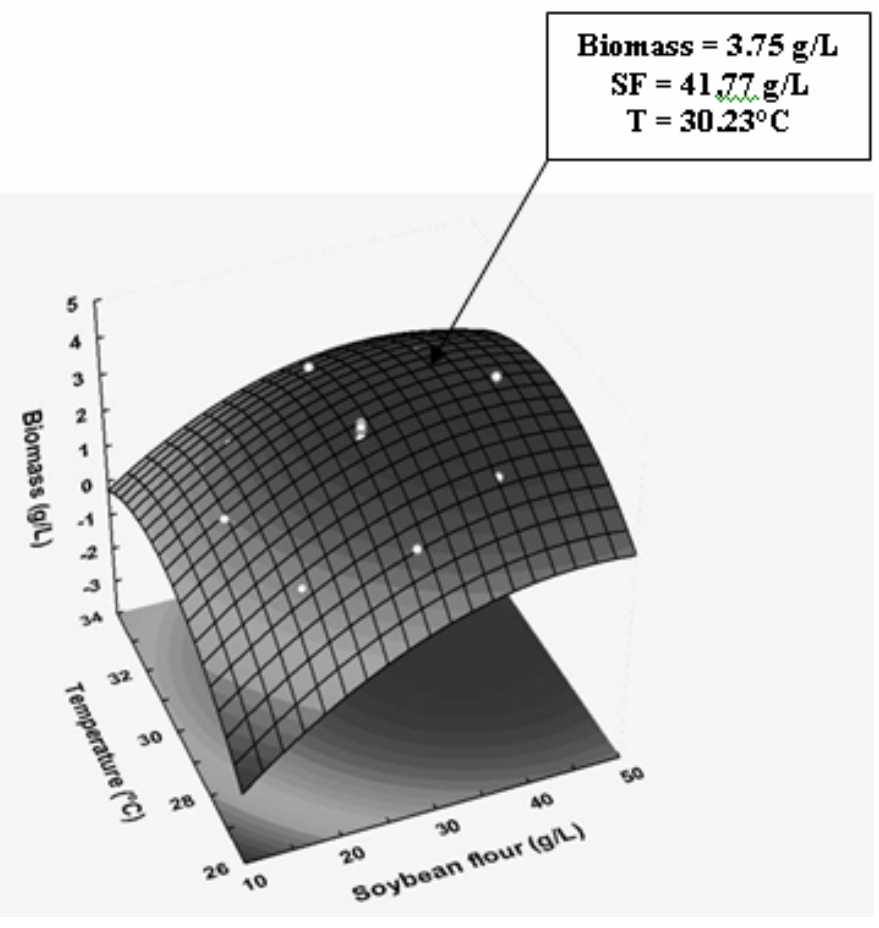

Figure 2. Three-dimensional response surface contour plot showing the simultaneous effects of soybean flour concentration and temperature on biomass concentration.

Although the statistical analysis revealed positive main linear effects of both independent variables (significant at $95 \%$ confidence level) either on CA or biomass concentrations, the effect of SF level was the stronger. However, this behavior was not linear, since the quadratic effects of theses variables were also significant. This means that the values of both responses increased up to a certain level when both variables were raised. As a result, there are two regions of temperature $\left(30-34^{\circ} \mathrm{C}\right)$ and SF concentration (35-45 g/L) where both responses reach maximum values. Although the interaction term $\left(x_{1} x_{2}\right)$ was not significant, it was kept in the model to allow for the error determination. Simultaneous regression by eqs. [3] and [4] provided maximum predicted values of CA concentration (640 $\mathrm{mg} / \mathrm{L}$ ) at $33.0{ }^{\circ} \mathrm{C}$ and $\mathrm{SF}=37.5 \mathrm{~g} / \mathrm{L}$, and of biomass concentration $(3.75 \mathrm{~g} / \mathrm{L})$ at $30.2{ }^{\circ} \mathrm{C}$ and $\mathrm{SF}=41.77 \mathrm{~g} / \mathrm{L}$, respectively. These predicted values are only $1.7 \%$ higher and $3.8 \%$ lower than the experimental ones, thus demonstrating the validity of the models employed.

The statistical significance of second-order model equations was confirmed by the F-test analysis of variance (ANOVA) and multiple regression (Tables 3 and 4). In fact, the computed F-values (27.08 for $\hat{y}_{2}$ and 3499 for $\hat{y}_{l}$ ) were much greater than the tabulated ones $\left[\mathrm{F}_{(2,11)}=11.63\right.$ and 14.54, respectively]. Whereas the lack of fit was insignificant for $\hat{y}_{2}[\mathrm{~F}$ $\left.=3.04<\mathrm{F}_{(2,11)}\right]$, that for $\hat{y}_{1}$, although significant $(\mathrm{F}=25.7)$, showed a very low pure error (1.1). In addition, the high values of the determination coefficients $\left(R^{2}=0.97\right.$ and 0.99 for biomass and $\mathrm{CA}$ concentrations, respectively) indicate that the models explained $97-99 \%$ of the variability data, and both regressions were statistically significant $(\mathrm{p}<0.0001)$ at $95 \%$ confidence level.

Table 3. Analysis of variance applied to the regression model used for the CA concentration $\left(\mathrm{R}^{2}=0.99\right)$.

\begin{tabular}{lcccccc}
\hline Source & Sum of squares & Degrees of freedom & Mean of square & F-value & Prob>F & Remarks \\
\hline Model & 191287.8 & 5 & 38257.6 & 3499.7 & 0.000000 & Significant \\
${ }^{+} b_{1}$ & 129675.7 & 1 & 129675.7 & 121571.0 & 0.000000 & Significant \\
$b_{11}$ & 52286.9 & 1 & 52286.9 & 49019.0 & 0.000000 & Significant \\
${ }^{\#} b_{2}$ & 9175.8 & 1 & 9175.8 & 8602.3 & 0.000000 & Significant \\
$b_{22}$ & 876.7 & 1 & 876.7 & 821.9 & 0.000001 & Significant \\
$b_{12}$ & 4.0 & 1 & 4.0 & 3.7 & 0.110567 & Significant \\
& 87.5 & 8 & 10.9 & & & \\
Residual & 82.1 & 3 & 27.4 & 25.7 & 0.001830 & Significant \\
Lack of fit & 5.3 & 5 & 1.1 & & &
\end{tabular}


Table 4. Analysis of variance applied to the regression model used for the biomass concentration $\left(R^{2}=0.97\right)$.

\begin{tabular}{|c|c|c|c|c|c|c|}
\hline Source & Sum of squares & Degrees of freedom & Mean of square & F-value & Prob $>$ F & Remarks \\
\hline Model & 6.70 & 5 & 1.34 & 27.09 & 0.000082 & Significant \\
\hline${ }^{+} b_{1}$ & 4.45 & 1 & 4.45 & 159.10 & 0.000056 & Significant \\
\hline$b_{11}$ & 0.72 & 1 & 0.72 & 25.76 & 0.003851 & Significant \\
\hline${ }^{\#} b_{2}$ & 0.36 & 1 & 0.36 & 13.01 & 0.015430 & Significant \\
\hline$b_{22}$ & 1.26 & 1 & 1.26 & 44.87 & 0.001121 & Significant \\
\hline$b_{12}$ & 0.04 & 1 & 0.04 & 1.43 & 0.285591 & $\begin{array}{c}\text { Not } \\
\text { Significant }\end{array}$ \\
\hline Residual & 0.39 & 8 & 0.05 & & & \\
\hline Lack of fit & 0.26 & 3 & 0.08 & 3.04 & 0.130860 & $\begin{array}{c}\text { Not } \\
\text { Significant }\end{array}$ \\
\hline Pure error & 0.14 & 5 & 0.03 & & & \\
\hline Total & 7.10 & 13 & & & & \\
\hline
\end{tabular}

Independent variables: ${ }^{+} 1$ = Soybean flour concentration; ${ }^{\#} 2=$ Temperature.

\section{Relationship between CA production and biomass growth}

As expected by the above trends, an almost linear relationship seems to hold between $\mathrm{CA}$ and biomass levels (Figure 3), which demonstrates that this strain is able to produce CA during growth. These results agree with those of Mayer and Deckwer (23), who observed that growth and production occurred simultaneously in the trophophase. CA production associated to cell growth was already detected utilizing soybean derivatives as nitrogen sources $(21,16)$. On the other hand, other authors observed that CA synthesis occurred during the trophophase, but the highest CA concentration was obtained during the stationary one $(1,33)$.

These results are of particular concern, when compared with those of Neves et al. (24), who utilized as industrial inoculum cells at the exponential growth phase after the same time $(24 \mathrm{~h})$ and obtained a maximum CA production of about $100 \mathrm{mg} / \mathrm{L}$ after a significantly longer time (about $70 \mathrm{~h}$ ). CA production comparable to that of the present study (672-681 $\mathrm{mg} / \mathrm{L}$ ) was observed with $S$. clavuligerus using $38 \mathrm{~g} / \mathrm{L}$ soy meal powder, $0.39 \mathrm{~g} / \mathrm{L} \mathrm{FeSO}_{4} \cdot 7 \mathrm{H}_{2} \mathrm{O}$ and $1.18 \mathrm{~g} / \mathrm{L}$ ornithine
(35).

As suggested by Butterworth (5), soybean proteins are important nutrients for CA production. The effectiveness of SF as a nitrogen source is in accordance with the results of Ortiz et al. (25), who observed CA productions in Erlenmeyer flasks increasing from 338 to $698 \mathrm{mg} / \mathrm{L}$ when $20 \mathrm{~g} / \mathrm{L} \mathrm{SF}$ substituted $10.9 \mathrm{~g} / \mathrm{L}$ soybean protein isolate as a nitrogen source. Higher CA levels (up to $1384 \mathrm{mg} / \mathrm{L}$ ) were obtained in medium containing glycerol and sucrose as carbon sources supplemented with amino acids (31), and in a glycerol-based medium with protein extract of soybean (1178 mg/L) (12).

As far as the effect of temperature is concerned, it is well known that an increase in this parameter stimulates CA production (34), even if it is very difficult to evaluate it, because of the simultaneous occurrence of temperaturedependent $\mathrm{CA}$ degradation. In fact, it has recently been demonstrated, in experiments with commercial CA, that an increase in temperature from 15 to $45{ }^{\circ} \mathrm{C}$ leads to a corresponding increase in the first-order degradation constant from 0.005 to $0.012 \mathrm{~h}^{-1}$ (29). 


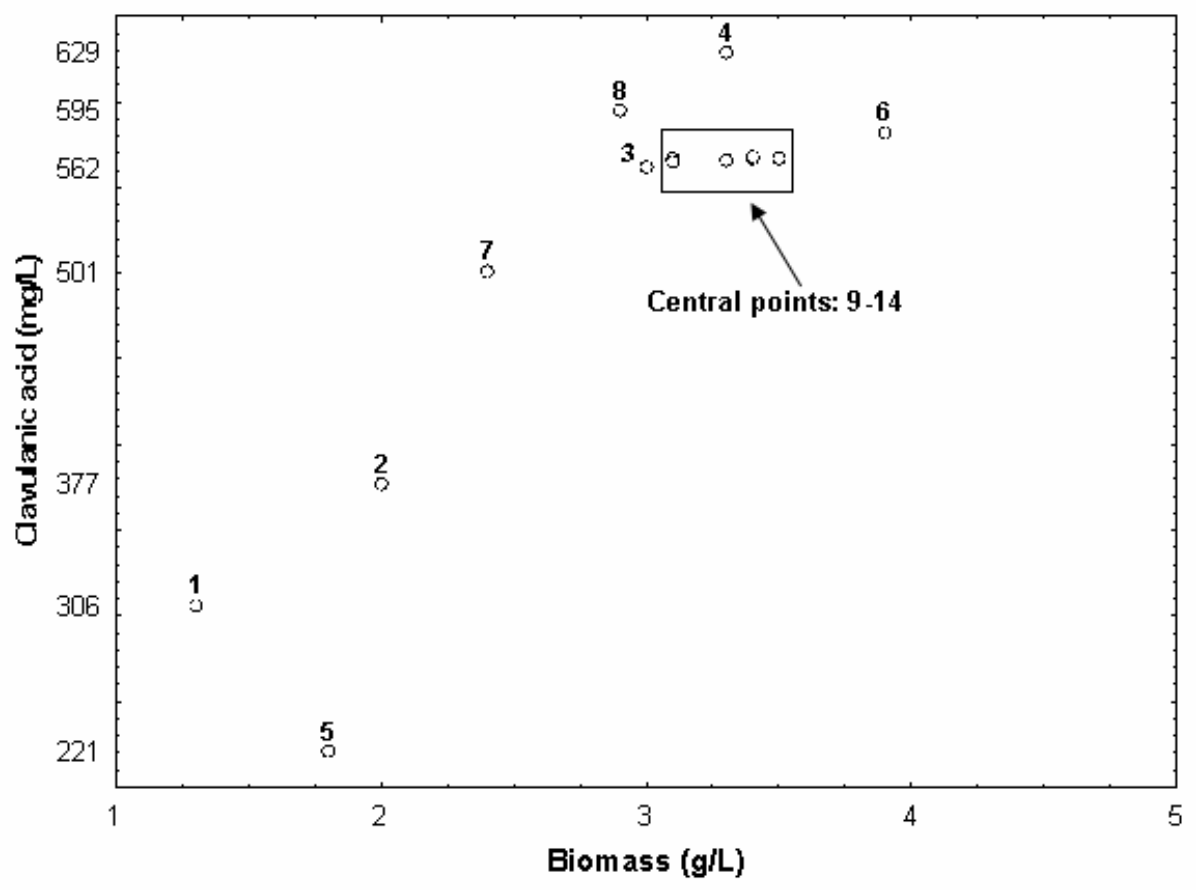

Figure 3. Relationship between biomass and CA concentrations obtained after $48 \mathrm{~h}$ of Streptomyces DAUFPE 3060 fermentations carried out according to the $2^{2}$ central composite design of Table 1.

\section{Fermentation under the best conditions}

Figure 4 shows the time behavior of CA production, biomass growth and glycerol consumption during the fermentation that provided the best results (run 4). It should be noticed that the highest cell concentration $(5.06 \mathrm{~g} / \mathrm{L})$ and $\mathrm{CA}$ production $(629 \mathrm{mg} / \mathrm{L})$ were both obtained before the complete consumption of glycerol, although after different times (72 and $48 \mathrm{~h}$, respectively). But the most evident result is that the CA concentration rapidly fell after $48 \mathrm{~h}$, as the likely result of higher degradation rate when compared to its production.

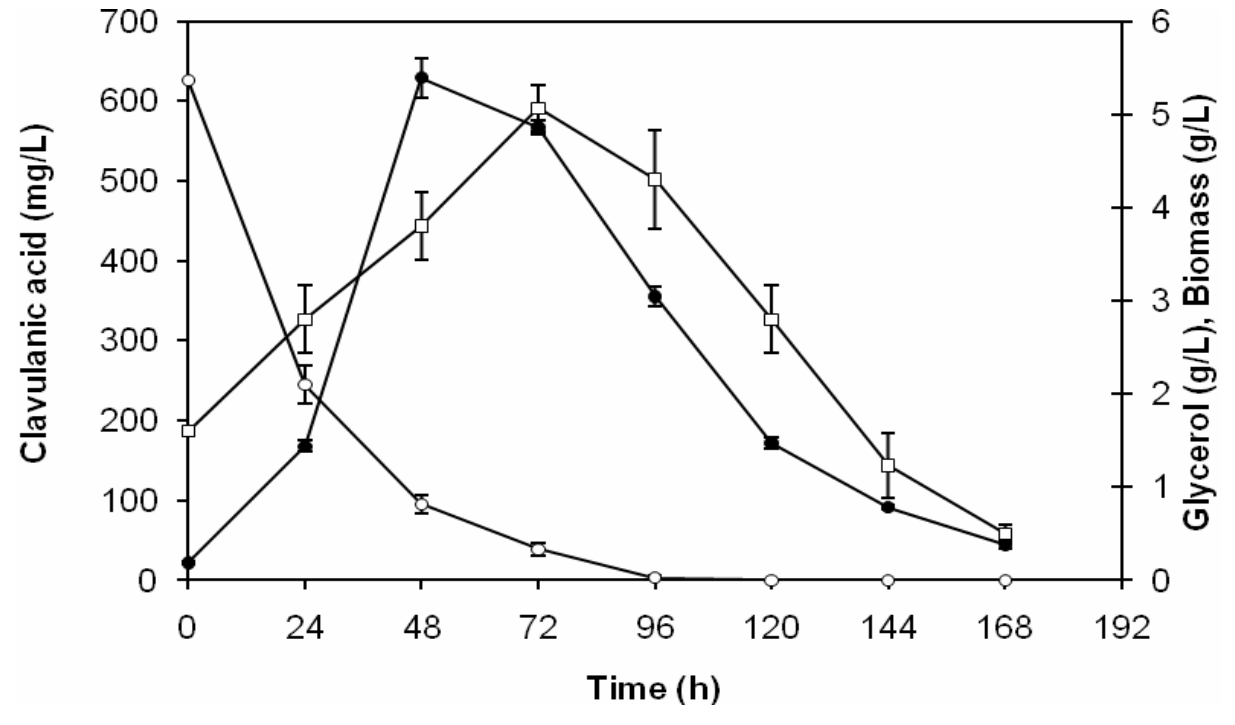

Figure 4. Time course of the concentrations of biomass $(\square)$, glycerol (०) and clavulanic acid (•) in shaken flasks. Temperature: 32 ${ }^{\circ} \mathrm{C}$; Soybean flour concentration: 40 g/L; Glycerol concentration: $5.0 \mathrm{~g} / \mathrm{L}$; 150 rpm; pH 6.0. 
Similar CA production simultaneous to growth, achievement of maximum CA concentration and subsequent quick degradation were observed by several authors $(8,23,26)$. In agreement with these findings, Lynch and Yang (21) observed that the rate of $\mathrm{CA}$ degradation during fermentation was comparable to that of its production and proposed that the degradation products could have been used by the microorganism for further production of the antibiotic. It was proposed that such degradation could be the result of the action of metabolites or enzymes produced by the strain (16), of compounds in the culture medium such as amino acids and inorganic materials (27) or of the autolysis resulting from the rising $\mathrm{pH}$, microbial decomposition, and re-metabolization (14).

\section{CONCLUSIONS}

These results on the whole suggest that a rigorous control of the residence time would be a fundamental requisite in scaling-up an industrial process for continuous clavulanic acid production by the new isolate Streptomyces DAUFPE 3060. The next effort in this direction will deal with the attempt to carry out this process in a bench-scale fermenter.

\section{ACKNOWLEDGEMENT}

The authors gratefully acknowledge the financial support of the Brazilian Research Funding Institutions FAPESP (process n. 05/60158-0) and CAPES.

\section{REFERENCES}

1. Baptista Neto, A.; Hirata, D.B.; Cassiano Filho, L.C.M.; Bellão, C.; Badino Jr, A.C.; Hokka, C.O. (2005). A study on clavulanic acid production by Streptomyces clavuligerus in batch, fed-batch and continuous processes. Braz. J. Chem. Eng. 22, 557-563.

2. Bird, A.E.; Bellis, J.M.; Gasson, B.C. (1982). Spectrophotometric assay of clavulanic acid by reaction with imidazole. Analyst 107, 1241-1245.

3. Box, G.E.P.; Wilson, K.B. (1951). On the experimental attainment of optimum conditions. J. Roy. Statist Soc. B 13, 1-45.

4. Bruns, R.E.; Scarminio, I.S.; Neto, B.B. (2006). Statistical Design Chemometrics. Elsevier, Amsterdam.

5. Butterworth, D. (1984). Clavulanic acid: properties biosynthesis, and fermentation. In: Vandamme, E.J. (ed). Biotechnology of Industrial Antibiotics. Marcel Dekker, New York, USA, p. 225-235.

6. Chen, K.C.; Lin, Y.H.; Tsai, C.M.; Hsieh, C.H.; Houng, J.Y. (2002). Optimization of glycerol feeding for clavulanic acid production by Streptomyces clavuligerus with glycerol feeding. Biotechnol. Lett. 24, 455-458.

7. Chen, Q.H.; He, G.Q.; Mokhtar, A.M.A. (2002). Optimization of medium composition for the production of elastase by Bacillus sp. EL31410 with response surface methodology. Enzyme Microb. Technol. 30, 667-672.

8. Chen, K.C.; Lin, Y.H.; Wu, J.Y.; Hwang, S.C. J. (2003). Enhancement of clavulanic acid production in Streptomyces clavuligerus with ornithine feeding. Enzyme Microb. Technol. 32, 152-156.

9. Chu, B.S.; Quek, S.Y.; Baharin, B.S. (2003). Optimization of enzymatic hydrolysis for concentration of vitamin $\mathrm{E}$ in palm fatty acid distillate. Food Chem., 80, 295-302.

10. Elander, R.P. (2003). Industrial production of $\square$-lactam antibiotics. Appl. Microbiol. Biotechnol. 61, 385-392.

11. Finlay, J.; Miller, L.; Poupard, J.A. (2003). A review of the antimicrobial activity of clavulanate. J. Antimicrob. Chemother. 52, 18-23.

12. Gouveia, E.R.; Baptista-Neto, A.; Badino-Jr, A.C.; Hooka, C.O. (2001). Optimisation of medium composition for clavulanic acid production by Streptomyces clavuligerus. Biotechnol. Lett. 23, 157-161.

13. Hae Bok, S. Demain, A.L. (1977). An improved colorimetric assay for polyols. Anal. Biochem. 81, 18-20.

14. Hu, W.S.; Brana, A.F.; Demain, A.L. (1984). Carbon source regulation of cephem antibiotic production by resting cell of Streptomyces clavuligerus and its reversal by protein synthesis inhibitors. Enzyme Microb. Technol. 6, 155-160.

15. Jensen, S.E.; Paradkar, A.S. (1999). Biosynthesis and molecular genetics of clavulanic acid. Antonie. Van. Leeuwenhoek. 75, 125-133.

16. Kenji, I.; Hung, T.V.; Lee, H.C.; Liou, K.; Shin, C.H.; Yoon, Y.J.; Sohng, J.K. (2006). Degradation of clavulanic acid during the cultivation of Streptomyces clavuligerus; instability of clavulanic acid by metabolites and proteins from the strain. J. Microbiol. Biotechnol. 16, 590-596.

17. Kim, I.C.; Kim, C.H.; Hong, S.I.; Kim, S.W. (2001). Fed-batch cultivation for the production of clavulanic acid by an immobilized Streptomyces clavuligerus mutant. World J. Microbiol. Biotechnol. 17, 869-872.

18. Kirk, S.; Avogmpme-Rossa, C.A.; Bushell, M.E. (2000). Growth 
limiting substrate affects antibiotic production and associated metabolic flues in Streptomyces clavuligerus. Biotechnol. Lett. 22, 1803-1809.

19. Lee, S.D.; Park, S.W.; Oh, K.K.; Hong, S.I.; Kim, S.W. (2002). Improvement for the production of clavulanic acid by mutant Streptomyces clavuligerus. Lett. Appl. Microbiol. 34, 370-375.

20. Liyana-Pathirana, C.; Shahidi, F. (2005). Optimization of extraction of phenolic compounds from wheat using response surface methodology. Food Chem. 93, 47-56.

21. Lynch, H.C.; Yang, Y. (2004). Degradation products of clavulanic acid promote clavulanic acid production in cultures of Streptomyces clavuligerus. Enzyme Microb. Technol. 34, 48-54.

22. Maranesi, G.L.; Baptista-Neto, A.; Hokka, C.O.; Badino-Jr, A.C. (2005). Utilization of vegetable oil in the production of clavulanic acid by Streptomyces clavuligerus ATCC 27064. World J. Microb. Biotechnol. $21,509-514$.

23. Mayer, A.F.; Deckwer, W.D. (1996). Simultaneous production and decomposition of clavulanic acid during Streptomyces clavuligerus cultivation. Appl. Microbiol. Biotechnol. 45, 41-46.

24. Neves, A.A.; Vieira, L.M.; Menezes, J.C. (2001). Effect of preculture variability on clavulanic acid fermentation. Biotechnol. Bioeng. 72, 628633.

25. Ortiz, S.C.A.; Hokka, C.O.; Badino-Jr, A.C. (2007). Utilization of soybean derivatives on clavulanic acid production by Streptomyces clavuligerus. Enzyme Microb. Technol. 40, 1071-1077.

26. Romero, J.; Liras, P.; Martin, J.F. (1984). Dissociation of cephamycin and clavulanic acid biosynthesis in Streptomyces clavuligerus. Appl. Microbiol. Biotechnol. 20, 318-325.

27. Roubos, J.A.; Krabben, P.; De Laat, W.T.A.M.; Babuska, R.; Heijen, J.J. (2002). Clavulanic acid degradation in Streptomyces clavuligerus fedbatch cultivations. Biotechnol. Prog. 18, 451-457.

28. Sánchez, S.; Olson, B. (2005). Microbial diversity - the bright and promising future of microbial manufacturing. Curr. Opin. Microbiol. 8 , 229-233.

29. Santos, V.C.; Brandão Pereira, J.F.; Brandão Haga, R.; Rangel-Yagui,
C.O.; Couto Teixeira, J.A.; Converti, A.; Pessoa Jr, A. (2009). Stability of clavulanic acid under variable $\mathrm{pH}$, ionic strength and temperature conditions. A new kinetic approach. Biochem. Eng. J. 45, 89-93.

30. Saudagar, P.S.; Survase, S.A.; Singhal, R.S. (2008). Clavulanic acid: A review. Biotechnol. Adv. 26, 335-351.

31. Saudagar, P.S.; Singhal, R.S. (2007). A statistical approach using L25 orthogonal array method to study fermentative production of clavulanic acid by Streptomyces clavuligerus MTCC 1142. Appl. Biochem. Biotechnol. 136, 345-359.

32. Tan, C.H.; Ghazali, H.M.; Kuntom, A.; Tan, C.P.; Ariffin, A.A. (2009). Extraction and physicochemical properties of low free fatty acid crude palm oil. Food Chem. 113, 645-650.

33. Teodoro, J.C.; Baptista-Neto, A.; Cruz-Hernández, I.L.; Hokka, C.O.; Badino-Jr, A.C. (2006). Influence of feeding conditions on clavulanic acid production in fed-batch cultivation with medium containing glycerol. Appl. Microbiol. Biotechnol. 72, 450-455.

34. Viana Marques, D.A.; Carneiro Cunha, M.N.; Araújo, J.M.; Barros-Neto, B.; Lima-Filho, J.L.; Converti, A.; Pessoa-Jr, A.; Porto, A.L.F. (2009). Screening of variables influencing the clavulanic acid production by Streptomyces DAUFPE 3060 strain. Appl. Biochem. Biotechnol., article online: doi 10.1007/s12010-009-8671-3.

35. Wang, Y. H.; Yang, B.; Renb, J.; Donga, M.L.; Liang, D.; Xua, A.L. (2005). Optimization of medium composition for the production of clavulanic acid by Streptomyces clavuligerus. Proc. Biochem. 40, 1161166.

36. Watve, M.G.; Tickoo, R.; Jog, M.M.; Bhole, B.D. (2001). How many antibiotics are produced by the genus Streptomyces? Arch. Microbiol. $176,386-390$.

37. Watve, M.G.; Shejval, V.; Sonawane, C.; Rahalkar, M.; Matapurkar, M.; Shouche, Y.; Patole, M.; Phadnis, N.; Champhekar, A.; Damle, K.; Karandikar, S.; Kshirsagar, V.; Jog, M. (2000). The 'K' selected oligophilic bacteria: a key to uncultured diversity? Curr. Sci. 78, 15351542. 